Thorax (1966), 21, 121.

\title{
Congenital coronary artery fistula
}

\author{
H. DEDICHEN, L. SKALLEBERG, AND CHR. CAPPELEN, JR. \\ From the Department of Surgery A, University of Oslo, Rikshospitalet, Oslo, Norway
}

Coronary artery fistulae are anomalies characterized by one or more abnormal communications between the coronary arteries and another part of the circulatory system. Haemodynamically they function as arteriovenous shunts, causing blood to bypass the capillary bed. Most of them are not, however, genuine arteriovenous communications in the strict sense of the term, since they empty into a heart chamber or into the pulmonary artery.

The anomaly is rare. So far only about 100 cases have been described. The aetiology, physiology, and anatomical variations are reviewed in recent publications by Gasul, Arcilla, Fell, Lynfield, Bicoff, and Luan (1960) and Upshaw (1962). The condition has lately become of increasing interest since it can be diagnosed by cardiac catheterization and coronary angiography, and most cases are amenable to surgical treatment at an acceptable risk.

This paper reports three cases with some remarks on the physiology of the condition and its treatment.

\section{CASE REPORTS}

CASE 1 M. P., a 44-year-old woman, was admitted in 1957. From the age of 20 she had been troubled by palpitations and dyspnoea on exercise. For the last six months she had had increasing dyspnoea and retrosternal pain. The heart action was regular but there were some extrasystoles. Blood pressure was $140 / 90 \mathrm{~mm}$. Hg. A high-frequency, continuous murmur was heard over the heart, maximal at the left lower sternal border. The E.C.G. was normal and radiographic examination revealed a relative heart volume of $390 \mathrm{ml} . / \mathrm{m}^{2}$ and some enlargement of the right atrium and ventricle. Right heart catheterization showed normal pressures in the right heart and pulmonary artery. A left-to-right shunt to the pulmonary artery was demonstrated and calculated to 2.91 . $/$ min., or $38.6 \%$ of the total pulmonary flow of $7 \cdot 51 . / \mathrm{min}$. At thoracotomy a plexus of vessels was found to connect the right coronary artery and the pulmonary artery (Fig. 1). A thrill was felt in the area. The plexus was temporarily clamped without a change in the heart rhythm or the E.C.G. The fistulous plexus was closed with multiple ligatures both at its coronary origin and close to the pulmonary artery. The thrill disappeared but the heart rhythm and E.C.G. remained unchanged. The post-operative course was uneventful. On examination three months later the patient had no dyspnoea, palpitations, or precordial pain. The E.C.G. was normal. A faint systolic as well as a faint diastolic murmur (but no continuous murmur) were heard over the heart.

From 1959 on she again developed dyspnoea and anginal pain on exertion, but the symptoms were moderate and progressed very little during the following years. On admission in 1965 the heart action was regular. Blood pressure was $145 / 95 \mathrm{~mm}$. Hg. A high-frequency, continuous murmur of moderate intensity was again heard at the left sternal border. An apical systolic murmur was also audible. The E.C.G. showed a digitalis effect but was otherwise normal. On radiological examination the heart contours were normal and the relative heart volume was calculated to $450 \mathrm{ml} . / \mathrm{m}^{2}$ Coronary angiography demonstrated an angiomatous connexion from the right coronary artery to the pulmonary artery (Fig. 2). Right heart catheterization showed normal pressures in the right heart and pulmonary artery. The oxygen saturation values were normal and did not reveal any left-to-right shunt. The hydrogen electrode, however, demonstrated a left-to-right shunt to the pulmonary artery, possibly also to the right ventricle. As her symptoms were modest and the shunt was apparently of small size, further surgical treatment is not considered necessary at present.

CASE 2 R. S., a 19-year-old girl, was admitted in 1960. When she was 10 years old a congenital heart malformation was suspected but was not further investigated. She had been asymptomatic. There was no cyanosis or finger clubbing. The heart action was regular. Blood pressure was $155 / 80 \mathrm{~mm}$. Hg. A continuous machinery murmur was heard over the apex and the left lower sternal border, and over the base of the heart a faint diastolic murmur was present. The E.C.G. was normal. Radiological examination revealed enlargement of both ventricles and the right atrium. Relative heart volume was $505 \mathrm{ml} . / \mathrm{m}^{2}$ Right heart catheterization showed normal pressures in the right heart and pulmonary artery. There was a left-to- 


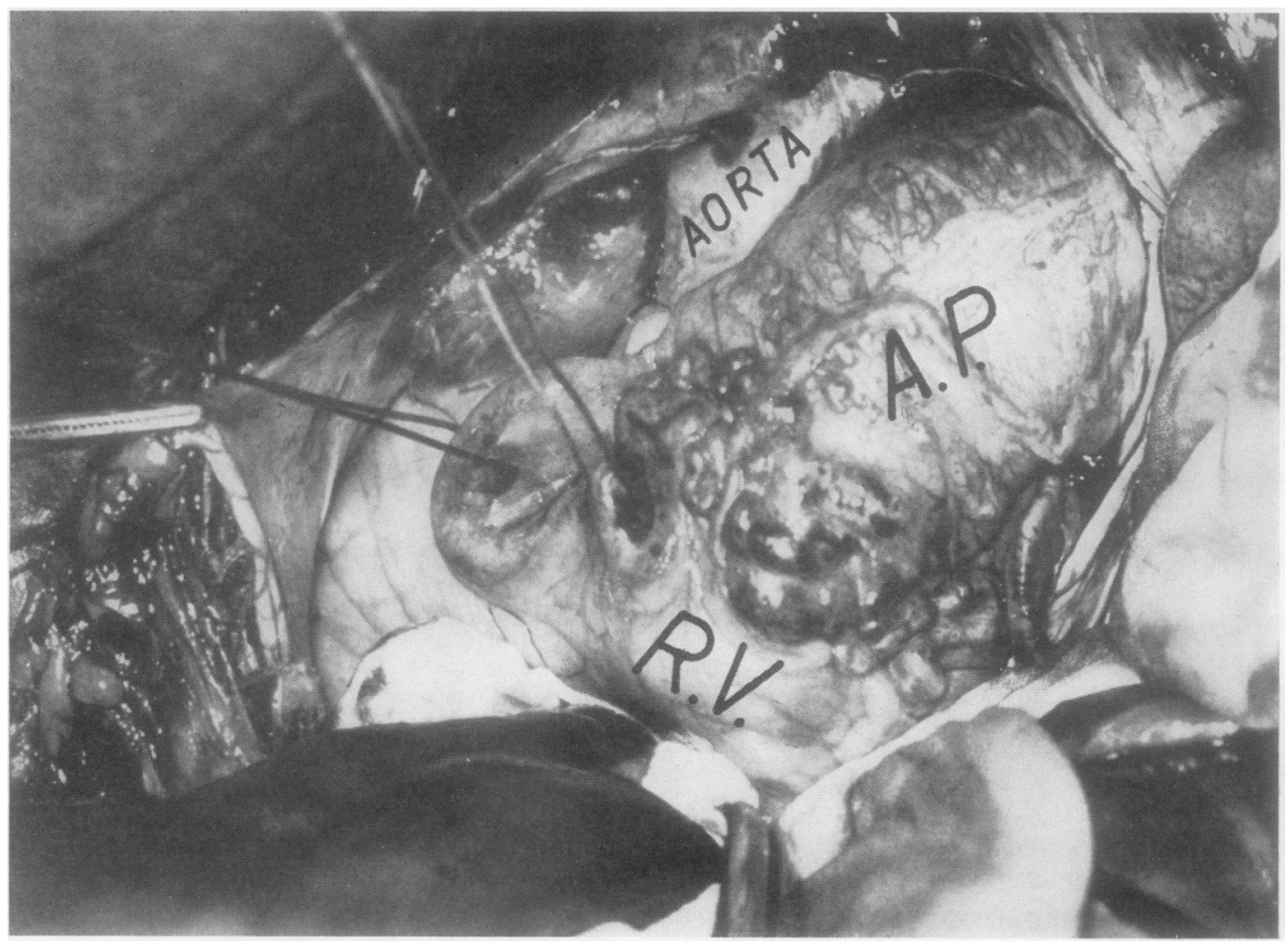

FIG. 1. Case 1. Photograph taken at operation.

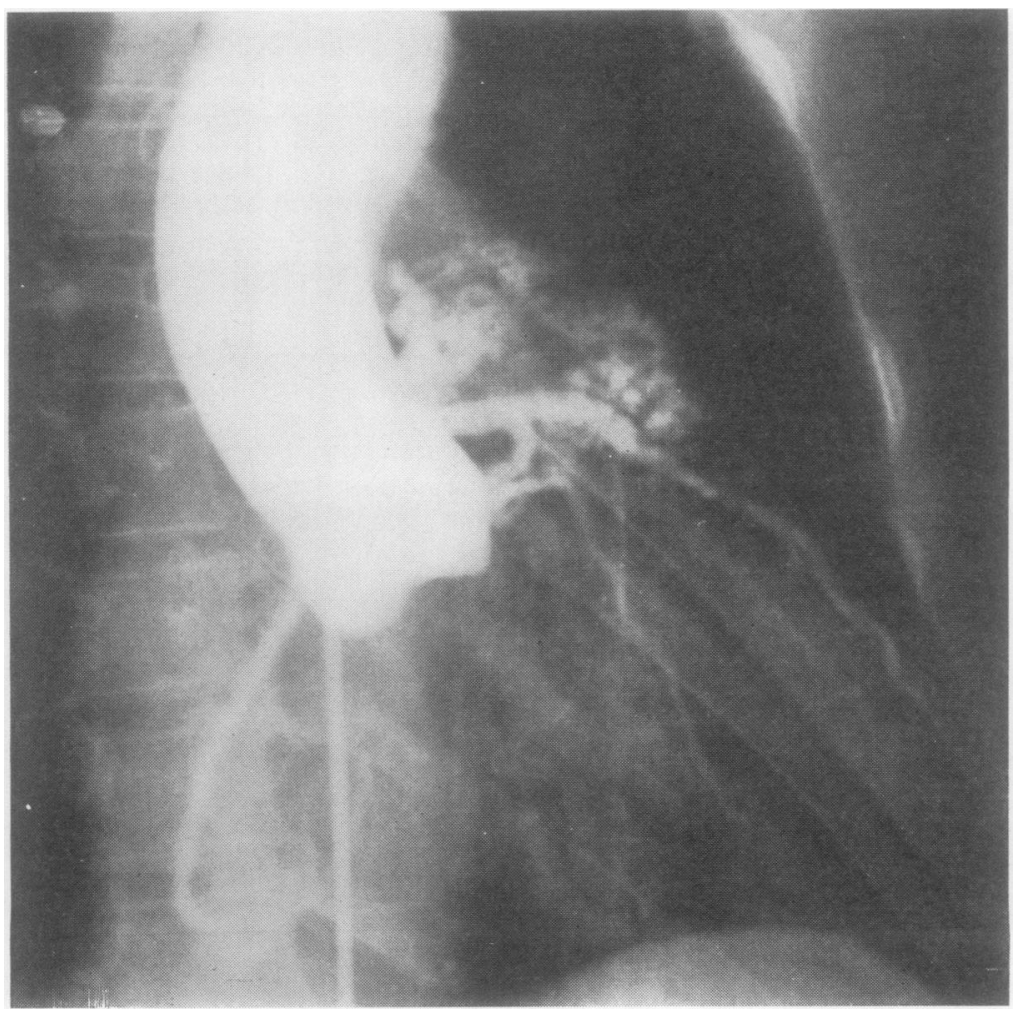

FIG. 12. Case 1. Coronary angiogram seven and $a$ half $c$ years after operation. 
right shunt at atrial level calculated to be $4.01 . / \mathrm{min}$., or $33.3 \%$ of the total flow of $12.01 . / \mathrm{min}$. in the pulmonary circulation.

She was operated on using an extracorporeal circulation. There was enlargement of all heart chambers, particularly of the right atrium. The right coronary artery was abnormally large and branched into a network of vessels emptying into the right ventricle below the pulmonary conus. An atrial septal defect, measuring $3 \times 3 \mathrm{~cm}$., was closed with direct sutures while the coronary artery fistulae were left open.

The post-operative course was uneventful. On examination three years later she remained asymptomatic. The E.C.G. was normal. A continuous machinery murmur was heard as before, but the diastolic murmur at the base of the heart had disappeared.

CASE 3 G. W., a 15-year-old girl, was admitted in 1964. A heart murmur was discovered when she was 7 years old. She was asymptomatic until the age of 12 , when she started to have dyspnoea on exertion. There was no cyanosis, finger clubbing, palpitation, or precordial pain. Heart action was regular and the blood pressure $120 / 75 \mathrm{~mm}$. Hg. The second heart sound was split. Along the lower right sternal border a high-frequency, continuous murmur was heard. The E.C.G. was normal. The phonocardiogram confirmed the above-mentioned murmur (Fig. 3). The radiographic examination showed normal heart contours, a relative volume of $350 \mathrm{ml} . / \mathrm{m}^{2}$, and normal pulmonary vascular markings. Right heart catheterization showed normal pressures in the right heart and pulmonary artery and normal oxygen saturation with no indication of left-to-right shunting. Vascular resistance in the pulmonary circulation was normal. The cardiac output was calculated to $4.51 . / \mathrm{min}$. (Fick principle).

Coronary angiography disclosed an abnormal right coronary artery, approximately $13 \mathrm{~mm}$. wide. About $40 \mathrm{~mm}$. from the aorta a descending branch of apparently normal size was visible. The fistula turned dorsally round the aorta. Contrast appeared in the left atrium simultaneously with increasing saturation of the aorta. No contrast could be seen in the pulmonary circulation (Fig. 4). At thoracotomy a markedly dilated right coronary artery was found. It divided into a normal descending branch and a fistulous vessel which turned dorsally and emptied directly into a pulmonary vein on the right side (Fig. 5). A distinct thrill was felt over the artery. Since occlusion of the fistula for 10 minutes affected neither the rhythm of the heart nor the E.C.G., the fistula was doubly ligated. The thrill disappeared.

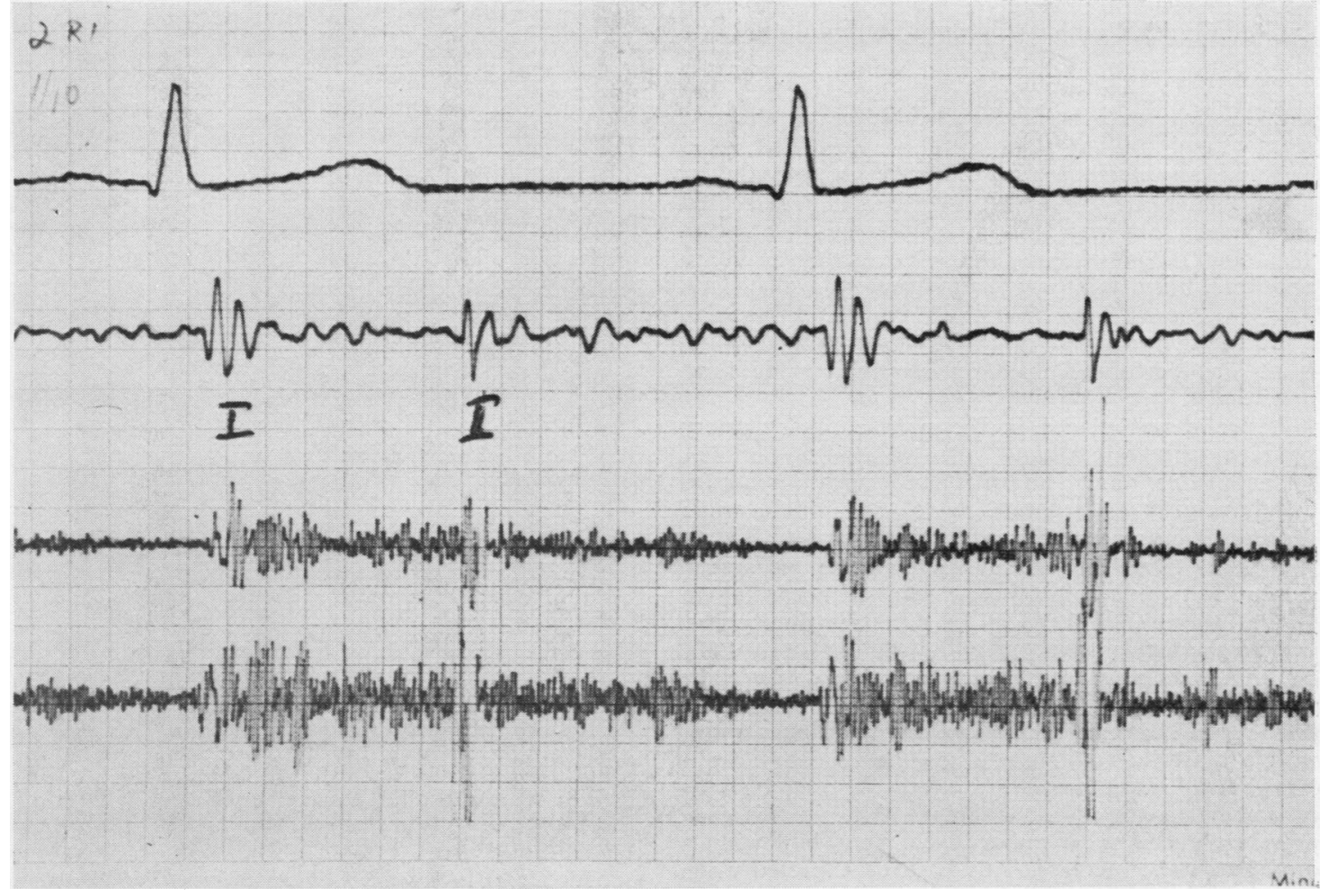

FIG. 3. Case 3. E.C.G. and phonocardiogram. 


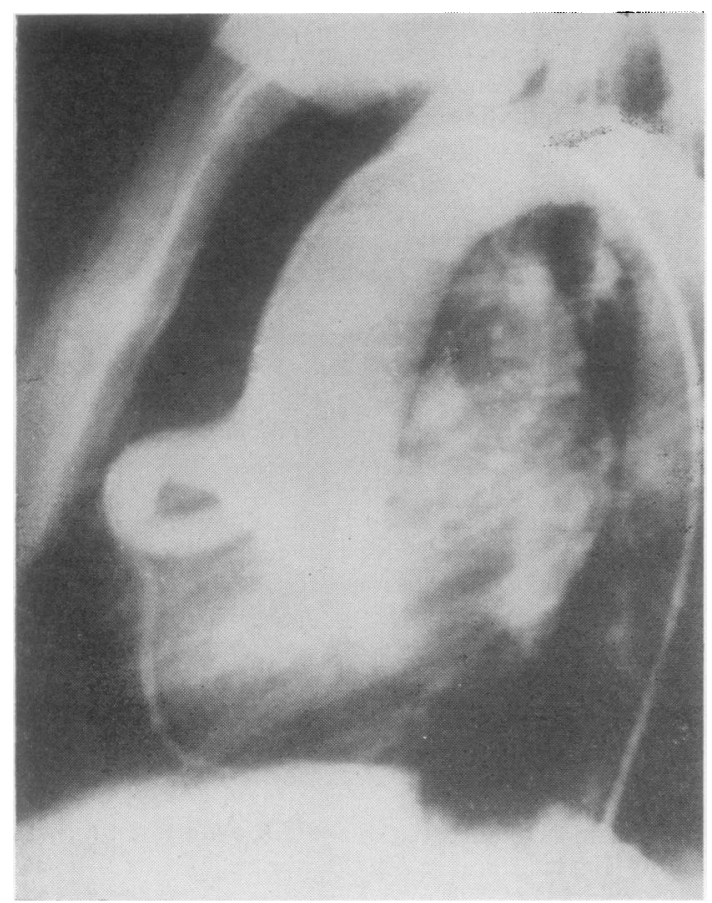

FIG. 4. Case 3. Coronary angiogram pre-operatively.

The post-operative course was uneventful. The E.C.G., however, showed a depression of the S-T segment and inverted $T$ waves. These were interpreted as mild anoxaemic changes. On examination four months later her exertional dyspnoea had decreased significantly but was still present on heavy exercise. The continuous machinery heart murmur had disappeared, but a faint systolic murmur was still heard. The E.C.G. was again normal.

During the operation on case 3, direct flow measurement was performed with an electromagnetic flowmeter. ${ }^{1}$

A probe was placed in the right coronary artery between the origin and the descending branch. Instantaneous and mean flow were recorded simultaneously on separate recorder channels, while the E.C.G. was recorded on a third channel (Fig. 6). We did not find it advisable to calibrate the system in situ, but the sensitivity was adjusted according to several previous calibrations of the same flow probe.

With the fistula open, a flow of approximately 1,800 $\mathrm{ml}$./min. was recorded. The instantaneous flow curve showed a pattern differing from the normal coronary flow curve. Normally, there is a markedly phasic flow with a diastolic maximum, since the coronary capillary bed is almost completely closed during myocardial contraction (Rushmer, 1961). In this case, however, there is a rather even flow but with a distinct systolic increase. This is to be expected when

'Nycotron blood flowmeter by Nycotron, Nycovn. 2, Oslo. Norway
T A B L E I

DATA FROM CARDIAC CATHETERIZATION

\begin{tabular}{|c|c|c|c|c|c|c|}
\hline \multirow[b]{2}{*}{ Site } & \multicolumn{2}{|c|}{ Case 1} & \multicolumn{2}{|c|}{ Case 2} & \multicolumn{2}{|c|}{ Case 3} \\
\hline & $\begin{array}{l}\text { Pres- } \\
\text { sure } \\
(\mathrm{mm} . \\
\mathrm{Hg})\end{array}$ & $\begin{array}{l}\text { Oxy- } \\
\text { gen } \\
\text { Sat. } \\
(\%)\end{array}$ & $\begin{array}{l}\text { Pres- } \\
\text { sure } \\
(\mathrm{mm} . \\
\mathrm{Hg})\end{array}$ & $\begin{array}{l}\text { Oxy- } \\
\text { gen } \\
\text { Sat. } \\
(\%)\end{array}$ & $\begin{array}{l}\text { Pres- } \\
\text { sure } \\
(\mathrm{mm} . \\
\mathrm{Hg})\end{array}$ & $\begin{array}{l}\text { Oxy- } \\
\text { gen } \\
\text { Sat. } \\
(\%)\end{array}$ \\
\hline $\begin{array}{l}\text { Superior vena cava } \\
\text { Right atrium } \\
\text { Right ventricle } \\
\text { Main pulmonary } \\
\text { artery . . } \\
\begin{array}{l}\text { Pulmonary artery } \\
\text { wedged .. }\end{array} \\
\begin{array}{l}\text { Femoral artery } \\
\text {. . }\end{array}\end{array}$ & $\begin{array}{r:r}3 & -1 \\
18 & -1 \\
14 & 6 \\
8 & 3\end{array}$ & $\begin{array}{l}70 \cdot 7 \\
70 \cdot 7 \\
70 \cdot 7 \\
78 \cdot 7\end{array}$ & $\begin{array}{r:r}5 & 2 \\
30 & 0 \\
23 & 10 \\
9 & 5\end{array}$ & $\begin{array}{l}83 \\
92 \\
86 \\
\\
88\end{array}$ & $\begin{array}{r:r}8 & 3 \\
21 & 0 \\
17 & 12 \\
13 & 5\end{array}$ & $\begin{array}{l}70 \\
75 \\
77 \\
\\
74\end{array}$ \\
\hline $\begin{array}{l}\text { Pulmonary flow } \\
\text { (1./min.) } \\
\text { Left-to-right } \\
\text { (1./min.). }\end{array}$ & \multicolumn{2}{|c|}{$7 \cdot 5$} & \multicolumn{2}{|c|}{$12 \cdot 0$} & \multicolumn{2}{|c|}{$4 \cdot 5$} \\
\hline
\end{tabular}

the flow is mainly dependent on the pressure gradient and not restricted by a myocardial throttling effect during systole.

With the probe still in position, the fistula was temporarily clamped, causing a marked decrease in blood flow. The exact flow is difficult to calculate because of the low sensitivity setting and E.C.G. interference with the flow signal. The E.C.G. was unaltered by the closure.

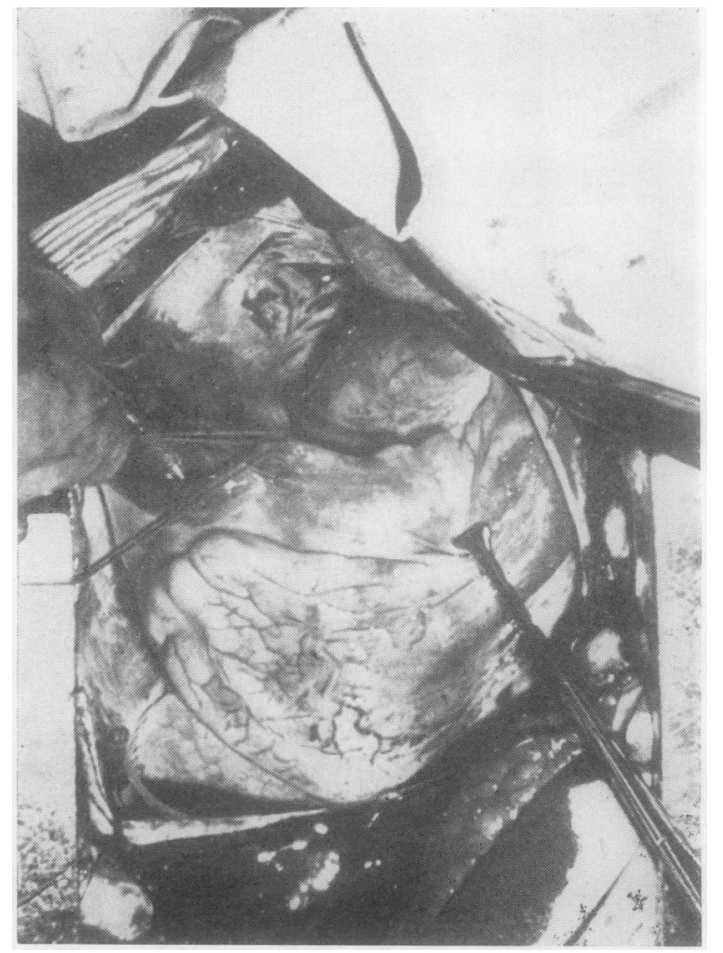

FIG. 5. Case 3. Photograph taken at operation. Coronary fistula pulled by thread slings. 


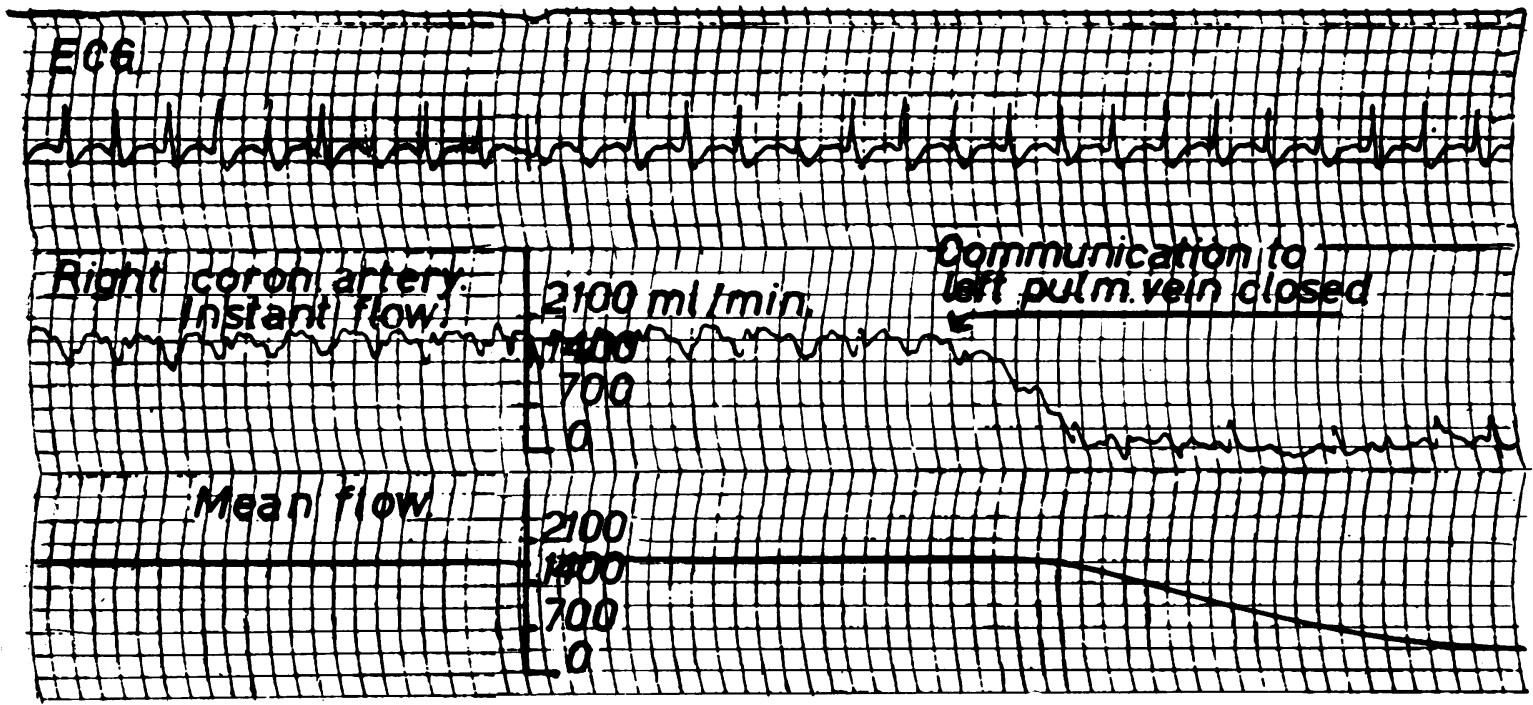

FIG. 6. Case 3. E.C.G. and blood-flow curves. During the registration the fistula was closed with a subsequently marked decrease in flow. The remaining spikes in the instantaneous flow curve are probably E.C.G. artefacts. The E.C.G. curve is unaltered by the closure.

\section{DISCUSSION}

The aetiology of coronary artery fistulae is obscure. The majority seem to be congenital and may result from defects in development in various stages of foetal life (Steinberg, Baldwin, and Dotter, 1958). Some occur with other congenital heart anomalies, and in one such case the mother was known to have had rubella during pregnancy (Schultz, 1958).

The anatomical variations are numerous with respect to origin and drainage areas as well as size. Sometimes a single direct fistula of even calibre is found (case 3 ). In other cases the fistula is tortuous or there is a plexus of multiple, tortuous vessels (cases 1 and 2). Aneurysms of various shapes and sizes occur. Some such cases may have been diagnosed as coronary artery aneurysms without recognition of their fistulous character.

Upshaw (1962) collected 73 cases published before 1962 and classified them according to origin and drainage area. Later publications have added 22 more cases, making a total of 98 including ours (Abbott, Rivarola, and Logue, 1961 ; Braudo, Javett, Zion, and Adler, 1962; Carmichael and Davidson, 1961 ; Cooley and Ellis, 1962 ; Haller and Little, 1963 ; Honey, 1964 ; Murray, 1963 ; Newcombe, Whitaker, and Keates, 1964 ; Sabiston, Ross, Criley, Gaertner, Neill, and Taussig, 1963).
CLASSIFICATION OF CORONARY ARTERY FISTULAE The following classification is according to point of origin :-

Right coronary artery

Left coronary artery 22

Common coronary artery 2

Both coronary arteries

An extra coronary artery

Unspecified

The following classification is according to recipient area :-

Right atrium or coronary sinus 29

Right ventricle

Pulmonary artery

Pulmonary vein

Left atrium

Left ventricle

A single ventricle

Unspecified

In 19 patients other congenital cardiac anomalies were also present:-

Persistent ductus arteriosus and pulmonary valvular atresia

Persistent ductus arteriosus

Ventricular septal defect

Aortic valvular atresia

Atrial septal defect 
The physiological effect of a coronary artery fistula depends on the shunted volume and the recipient area, while minor variations in the point of origin are probably of less importance.

The shunted volume varies considerably. Volumes from 0.7 to $6.43 \mathrm{l} / \mathrm{min}$. are observed, representing from 11.1 to $68.9 \%$ of the flow in the pulmonary circulation (Tables II and III). The shunted volume is influenced by the diameter of the fistula, its length and shape, and on the pressure gradient between the origin and outlet. When the fistula passes through the myocardium, a choking effect on the flow will be present during systole. When the fistulous tract is extramural, no such effect will occur. To the best of our knowledge, our case 3 is the first in which blood flow has been measured directly. The fact that this flow is rather even and with a systolic maximum shows that the pressure gradient from the aorta to the pulmonary vein is the main factor in this case. When the fistula empties into the left ventricle the flow will presumably be confined to diastole. If there is any systolic flow, it must be reversed. When the fistula empties into the right ventricle, the systolic pressure in this chamber may also be of importance. Only direct flowmetry will prove whether or not there is a phasic flow with diastolic maximum in these cases.

A coronary artery fistula will influence the circulation unfavourably by several mechanisms:

(1) Like all arteriovenous shunts, it causes an increase in cardiac output and thereby an increased load on the left ventricle. Steinberg et al. (1958) state: 'Given sufficient shunt volume for a sufficient period of time it will inevitably lead to left ventricular hypertrophy and cardiac failure.'

(2) When emptying into the pulmonary artery, the fistula will cause an extra load on the pul-

T A B L E I I

SHUNT VOLUMES AND PULMONARY ARTERY PRESSURES

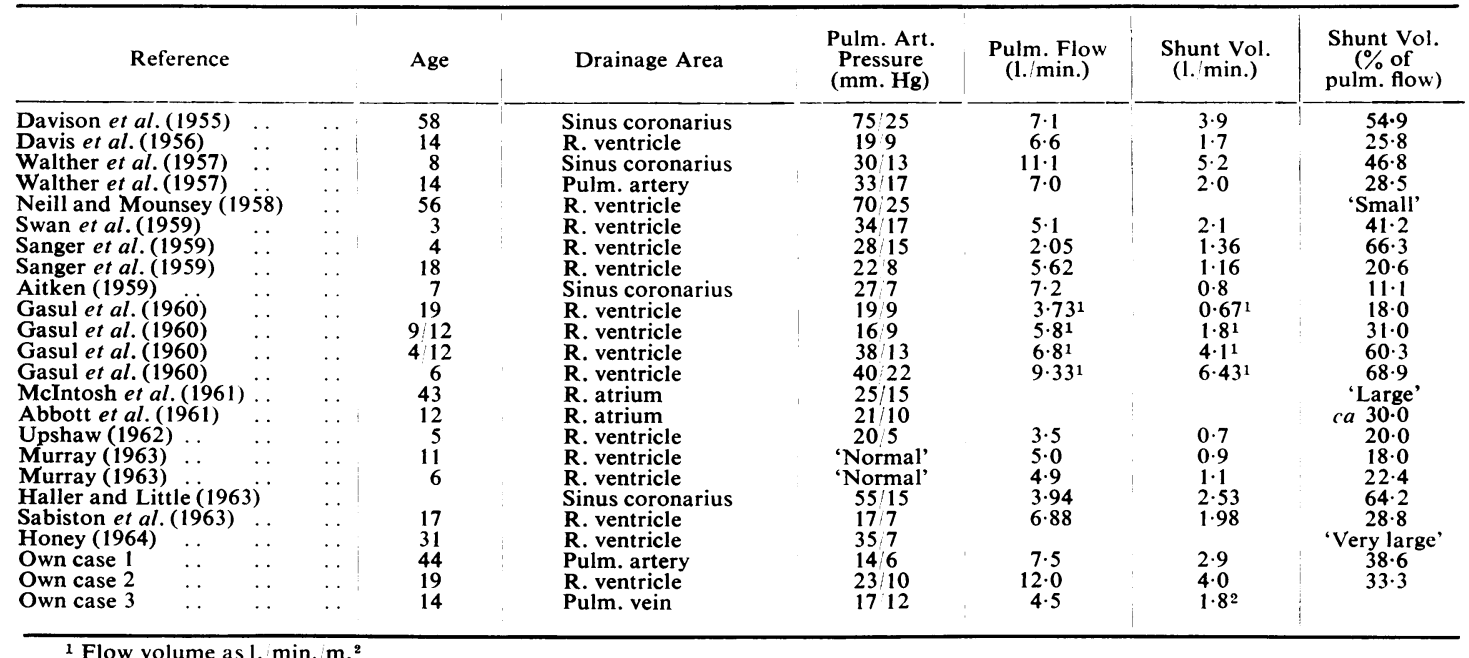

2 Registered by direct flowmetry during operation.

T A B L E II I

SHUNT VOLUMES AND PULMONARY ARTERY PRESSURES IN PATIENTS WITH CORONARY ARTERY FISTULA AND PERSISTENT DUCTUS ARTERIOSUS

\begin{tabular}{|c|c|c|c|c|c|c|c|c|}
\hline Reference & & Age & Drainage Area & $\begin{array}{c}\text { Pulm. Art. } \\
\text { Pressure } \\
(\mathrm{mm} . \mathrm{Hg})\end{array}$ & $\begin{array}{l}\text { Pulm. } \\
\text { Flow } \\
\text { (1. } \text { min.) }\end{array}$ & \multicolumn{2}{|c|}{$\begin{array}{l}\text { Shunt Volume } \\
(1 . / \mathrm{min} .)\end{array}$} & $\begin{array}{l}\text { Shunt Volume } \\
(\% \text { of pulm. flow) }\end{array}$ \\
\hline Schultz (1958) $\quad \ldots$ & $\cdots$ & 11 years & R. ventricle & 2310 & $8 \cdot 3$ & $3 \cdot 7$ & $\begin{array}{l}1 \cdot 6 \\
2 \cdot 1\end{array}$ & $\begin{array}{l}19.3 \text { in fistula } \\
25.3 \text { in ductus }\end{array}$ \\
\hline Bosher et al. (1959) & . & 4 months & R. atrium & $54: 24$ & $5 \cdot 3$ & $4 \cdot 1$ & $\begin{array}{l}0 \cdot 6 \\
3 \cdot 5\end{array}$ & $\begin{array}{l}11.3 \text { in fistula } \\
66.0 \text { in ductus }\end{array}$ \\
\hline Gasul et al. (1960) & $\cdots$ & 2 months & R. ventricle & 209 & $8 \cdot 31$ & $4 \cdot 2^{1}$ & $\begin{array}{l}2 \cdot 6^{1} \\
1 \cdot 6^{1}\end{array}$ & $\begin{array}{l}31.3 \text { in fistula } \\
19.3 \text { in ductus }\end{array}$ \\
\hline
\end{tabular}

1 Flow volume as $1 . \min . / \mathrm{m}^{2}$ 
monary circulation. When emptying into the right atrium or ventricle, it represents an extra load on the right ventricle as well. Right heart catheterization in published cases reveals that slight to moderate pulmonary hypertension is not uncommon in these patients (Table II). This leads to hypertrophy of the right ventricle and pulmonary congestion.

(3) A short, wide fistula from the coronary artery tree to areas with considerably lower pressures will drain away a great part of the blood in the coronary system. This may cause a reduction in the pressure gradient over the myocardial capillaries. It is a common clinical experience that arteriovenous fistulae in the extremities may lead to ischaemic phenomena distally to the fistula. By analogy, one would expect coronary artery fistulae to be accompanied by myocardial ischaemic manifestations. This is rare. Four cases with E.C.G. changes suggesting myocardial ischaemia have been published (Edwards, Gladding, and Weir, 1958 ; Knoblich and Rawson, 1956 ; Sabiston et al., 1963 ; Valdivia, Rowe, and Angevine, 1957). One case had angina of effort (Abbott et al., 1961), as had our case 1.

The condition may be asymptomatic, but, as a rule, varying degrees of heart failure gradually develop, with exertional dyspnoea as the most common symptom. The predominating physical sign is a continuous, systolic-diastolic heart murmur. It imitates the murmur from a persistent ductus arteriosus, but often has a particularly superficial character and is usually confined to the lower sternal border. In some cases it is not continuous throughout the heart cycle but confined to systole or diastole (Neill and Mounsey, 1958). Radiographic examination may show enlargement of one or more heart chambers and increased pulmonary vascular markings. The E.C.G. changes are non-specific. The blood pressure may show high pulse pressure. Subacute bacterial endocarditis occurs but is rare (Abbott et al., 1961 ; Sabiston et al., 1963).

The condition should be suspected when a continuous heart murmur with somewhat atypical character and localization is heard. Right heart catheterization may reveal a fistula to the right heart or pulmonary artery but not to the pulmonary vein or left heart. Coronary angiography usually demonstrates the entire course of the fistula and confirms the diagnosis. A definite preoperative diagnosis is thus ensured in most cases.

Some patients have a normal life span, and the oldest so far known died at 85. Others develop heart failure leading to death at an early age
(Davison, McCracken, and Mcllveen, 1955 ; Honey, 1964). Experiences from these cases indicate that such fistulae should be surgically closed in all patients with subjective symptoms. The risk of complications will probably increase with increasing age of the patient, as will the operative risk if surgical treatment is postponed for any length of time. It is probably advisable to operate on asymptomatic patients once the diagnosis has been confirmed. In asymptomatic patients with small shunt flows, surgical treatment may safely be postponed until late childhood.

Most operations can be performed with conventional anaesthesia, but extracorporeal circulation should be at hand when angiomatous fistulae or large aneurysms are present. When the fistula is defined, it should be temporarily clamped for at least 10 minutes while the heart and the E.C.G. are observed. If no significant changes are seen, the fistula is definitively closed. In angiomatous fistulae, multiple ligatures may be required.

A survey of 27 patients operated on up to 1961 is presented by Abbott et al. (1961). Most of the patients were treated by ligature of the supplying coronary artery. One post-operative death occurred in a child with a persistent ductus arteriosus and a coronary artery fistula, one patient had no benefit from the operation, and the rest were definitely improved. Later publications, including our own, provide a record of a further 16 patients operated on with good results (Abbott et al., 1961 ; Braudo et al., 1962 ; Carmichael and Davidson, 1961 ; Cooley and Ellis, 1962; Haller and Little, 1963; Murray, 1963 ; Sabiston et al., 1963). One patient died following 'banding' of the pulmonary artery as a ventricular septal defect was suspected (Newcombe et al., 1964).

Semantically, coronary arteriovenous fistulae, coronary-pulmonary fistulae, and coronary-cardiac fistulae can be segregated, but this classification ignores the physiological facts. An anatomical classification can be made according to the point of origin and emptying area, but, due to the great variations and numerous possible combinations, this is not satisfactory.

We are of the opinion that the following facts are of importance haemodynamically, and they supply a basis for a physiological classification:-

(1) When the fistula empties into the pulmonary vein, the left atrium or left ventricle, the increase in strain is confined to the left ventricle. These fistulae cannot be disclosed by right heart catheterization. They represent less than $10 \%$ of all cases. 
(2) When the fistula empties into the right heart or the pulmonary artery, the increased load also affects the right ventricle and the pulmonary circulation. These fistulae are disclosed and their flow is calculated by right heart catheterization.

In roughly $20 \%$ of all cases, other cardiovascular malformations usually dominate the symptomatology, influence the prognosis, and decide what treatment is to be given.

\section{SUMMARY}

Three cases of coronary artery fistulae are reported. In two cases an angiomatous fistula to the pulmonary artery and the right ventricle respectively were found; in the third case there was a single, wide fistula from the right coronary artery to a pulmonary vein. During operation on case 3, direct flow measurement was performed with an electromagnetic flowmeter, and a flow of approximately $1,800 \mathrm{ml} . / \mathrm{min}$. through the fistula was recorded. The instantaneous flow pattern showed a rather even flow but with a systolic increase.

A coronary artery fistula influences the circulation unfavourably by (1) an increased load on the left ventricle, (2) an increased load on the right ventricle and pulmonary circulation when emptying into the right heart or pulmonary artery, and (3) draining away a part of the blood from the coronary circulation.

The condition may be asymptomatic; but, as a rule, varying degrees of heart failure gradually develop with exertional dyspnoea as the most common symptom. It is suggested that such fistulae should be surgically closed once the diagnosis is confirmed.

The following classification of coronary artery fistulae is suggested: (1) Fistulae emptying into the pulmonary vein or the left heart. The increased strain is confined to the left ventricle. These fistulae are not detected by right heart catheterization. (2) Fistulae emptying into the right heart or pulmonary artery. The increased load will also affect the right ventricle and the pulmonary cir- culation. These fistulae are disclosed and their flow calculated by right heart catheterization.

\section{REFERENCES}

Abbott, O. A., Rivarola, C. H., and Logue, R. B. (1961). Surgical correction of coronary arteriovenous fistula. $J$, thorac, cardiovasc. Surg., 42, 660.

Aitken, G. J. (1959). Coronary arterio-venous fistula. Case report and discussion of the clinical picture. Scot. med.J., 4, 27.

Bosher, L. H., jun., Vasli, S., McCue, C. M., and Belter, L. F. (1959). Congenital coronary arteriovenous fistula associated with large patent ductus. Circulation, 20, 254.

Braudo, J. L., Javett, S. N., Zion, M. M., and Adler, D. I. (1962). Congenital coronary arteriovenous fistula. Brit. med. $J, 1,601$.

Carmichael, D. B., and Davidson, D. G. (1961). Congenital coronary arteriovenous fistula. Amer. J. Cardiol., 8, 846.

Cooley, D. A., and Ellis, P. R. (1962). Surgical considerations of coronary arterial fistula. Ibid., 10, 467.

Davis, C., jun., Dillon, R. F., Fell, E. H., and Gasul, B. M. (1956). Anomalous coronary artery simulating patent ductus arteriosus. J. Amer. med. Ass., 160, 1047.

Davison, P. H., McCracken, B. H., and McIlveen, D. J. S. (1955) Congenital coronary arterio-venous aneurysm. Brit. Heart J., $17,569$.

Edwards, J. E., Gladding, T. C., and Weir, A. B., jun. (1958). Congenital communication between the right coronary artery and the right atrium. J. thorac. Surg., 35, 662.

Gasul, B. M., Arcilla, R. A., Fell, E. H., Lynfield, J., Bicoff, J. P. and Luan, L. L. (1960). Congenital coronary arteriovenous fistula. Clinical, phonocardiographic, angiocardiographic and hemodynamic studies in five patients. Pediatrics, 25,531 .

Haller, J. A., and Little, J. A. (1963). Diagnosis and surgical correction of congenital coronary artery-coronary sinus fistula. Circulation, $27,939$.

Honey, M. (1964). Coronary arterial fistula. Brit. Heart J., 26, 719.

Knoblich, R., and Rawson, A. J. (1956). Arteriovenous fistula of the heart. Amer. Heart J., 52, 474.

McIntosh, H. D., Sleeper, J. C., Thompson, H. K., jun., Sealy, W. C., and Young, W. G., jun. (1961). Preoperative evaluation of a continuous murmur in the chest. Arch. Surg., 82, 74.

Murray, R. H. (1963). Single coronary artery with fistulous communication. Report of two cases. Circulation, 28, 437.

Neill, C., and Mounsey, P. (1958). Auscultation in patent ductus arteriosus; with a description of two fistulae simulating patent ductus. Brit. Heart J., 20, 61 .

Newcombe, C. P., Whitaker, W., and Keates, P. G. (1964). Coronary arterio-venous fistulae. Thorax, 19, 16.

Rushmer, R. F. (1961). Cardiovascular Dynamics, 2nd ed.,pp. 216-218. W. B. Saunders, Philadelphia and London.

Sabiston, D. C., jun., Ross, R. S., Criley, J. M., Gaertner, R. A., Neill, C. A., and Taussig, H. B. (1963). Surgical management of congenital lesions of the coronary circulation. Ann. Surg., 157, cong.

Sanger, P. W., Taylor, F. H., and Robicsek, F. (1959). The diagnosis and treatment of coronary arteriovenous fistula. Surgery, 45, 344.

Schultz, J. (1958). Coronary arteriovenous aneurysm: Review of the literature. Amer. Heart J., 56, 431.

Steinberg, I., Baldwin, J. S., and Dotter, C. T. (1958). Coronary arteriovenous fistula. Circulation, 17, 372.

Swan, H., Wilson, J. N., Woodwark, G., and Blount, S. G. (1959). $\frac{D}{O}$ Surgical obliteration of a coronary artery fistula to right ventricle. Arch. Surg., 79, 820.

Upshaw, C. B., jun. (1962). Congenital coronary arteriovenous fistula. $N$ Report of a case with an analysis of seventy-three reported cases. Amer. Heart J., 63, 399.

Valdivia, E., Rowe, G. G., and Angevine, D. M. (1957). Large con genital aneurysm of the right coronary artery. Arch. Path., 63, 168. W

Walther, R. J., Starkey, G. W. B., Zervopolus, E., and Gibbons, G. A. (1957). Coronary arteriovenous fistula. Amer. J. Med., 22, 213. 